\title{
JUURNAL_RU
}

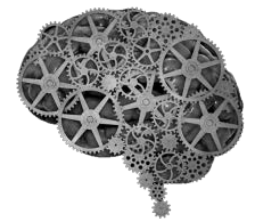

COMPANY GROUP "INTELLEKT"

Бакланова Л.А. МАОУ «СОШ №65 с углубленными изучением английского языка» Пермь, Россия

doi: 10.18411//j2016-9-2-01

idsp 000001: lj2016-18-2-01

\section{Воспитание гражданина}

\section{Аннотация}

Смена ценностей подрастающего поколения, нежелание и неумение вести диалог двух или нескольких культур с акцентом на Российскую действительность побудило обратить внимание на нравственные и патриотические вопросы воспитания детей в комплексе: на уроках английского языка, во внеклассной деятельности и в классном руководстве.

The teen's values of life have changed. They hardly ever can lead the dialogue of two or more cultures with foreigners with the accent on Russian reality. All these motivated me to pay attention on the problem of Russian children patriotism at English lessons, class and school activities.

Ключевые слова: патриотическое воспитание, ценности, культура, диалог двух культур. Patriotic education, values, culture, dialogue of two cultures.

Свою педагогическую задачу я вижу в воспитании патриота России, «ориентированного на приоритет национальных российских ценностей при уважении к ценностям других культур; стремящегося в разумных пределах сочетать личные интересы с интересами общества, государства и других людей; способного правильно выбирать жизненные цели» (Н.Д. Никандров)[4,6]. Моя миссия - воспитание учащихся в интернациональном духе, уважающих права и свободы личности, обладающих высокой нравственностью и проявляющих терпимость, уважительное отношение к языку, традициям и культуре других народов. 
Воспитание гражданского самосознания является сердцевиной воспитательной системы школы. Содержание этого процесса - совместная деятельность взрослых и детей по изменению условий жизни, когда происходит историческая преемственность поколений, сохранение, распространение и развитие национальной культуры, воспитание бережного отношения к историческому и культурному наследию народов России.

В наши дни Россия переживает духовный кризис, который выражается в «угасании» патриотических чувств, смене нравственных ценностей. Недостаточно значимы стали традиции и обычаи семьи [4, 11]. Современные дети испытывают большое влияние средств массовой информации, Интернета. Но не только музыка и шоу программы должны интересовать наших детей. Такие темы как патриотизм, любовь к родине, уважение к семейным традициям, к своей и другим культурам должны обсуждаться и в семье, и в школе. Это побудило меня задать себе вопрос: «Как помочь ребёнку самоидентифицироваться и уважительно относится к родной и другим культурам?»

Необходимо было разработать систему урочной и внеурочной деятельности: определить цели и задачи, содержание (усиление гражданскопатриотического компонента), методы, приёмы, способы деятельности, которые должны приводить к планируемому результату - воспитанию гражданина, любящего свою Родину и достойно представляющего родную культуру.

В диалоге культур важную роль играет знание иностранного языка, которое позволяет взаимодействовать с представителями другой культуры на более качественном уровне. Мои ученики должны достичь функциональной грамотности во владении иностранным языком (ИЯ) - уровня В2-С1. Для этого я создаю условия на уроке и во внеурочной деятельности для максимального развития коммуникативных способностей обучающихся, психологической и лингвистической готовности к общению на ИЯ. Главным в своей педагогической деятельности я считаю не только обучение, но и воспитание гражданина своей Родины, способного вести успешный диалог с представителями других культур.

Эту цель я реализую через решение следующих задач:

- воспитывать патриота своей семьи, школы, города, страны; 
- формировать мотивацию к изучению английского языка, как средства

- общения с представителями другой культуры;

- развивать коммуникативную компетенцию.

Свой опыт педагогической деятельности по теме «Воспитание гражданина на уроках английского языка, во внеурочной деятельности и классном руководстве» я обобщила на городских и районных научно-практических конференциях, на заседаниях городской проблемной группы по классному руководству. Я учу детей занимать и отстаивать гражданскую позицию, стараюсь пробудить в детях неравнодушие, соучастие и сопереживание, способствую развитию эмпатии.

Дети не готовятся к будущей жизни, а живут «здесь и сейчас». Важно создать условия, при которых они смогут проявить себя, сделать осознанный выбор, научиться взаимодействовать в социуме, имея свою позицию. Поэтому я личным примером показываю, как можно выразить свою позицию. Я откликнулась на трагические события в стране и мире. Моя работа «Нет терроризму! Ключи к социальному обществу» была представлена на конкурс телекоммуникационных проектов «Личность и общество в России» и размещена на сайте школы. Она вызвала волну поддержки, которая вылилась в акцию газеты Кировского района «Время Закамское». Газета опубликовала статьи, составленные на основе сочинений моих учащихся из разных классов. Моя победа в городском конкурсе «Династии в образовании» в номинации «Из века в век» показала ученикам, что нужно знать свои корни. Мои ученики также проявили интерес к своим родословным и подготовили материалы к научнопрактической конференции.

Мой опыт педагогической деятельности показывает, что изучаемая на уроках тема интересна в том случае, если она имеет личностный смысл для ребёнка и социально-практическое значение. Организую работу на уроке так, чтобы учащиеся «пропустили каждую тему через себя», структурируя содержание с акцентом на российскую действительность, активизирую чувства и эмоции, чтобы материал остался в памяти и стал жизненным опытом ученика.

Решая задачи формирования поликультурной личности, ее гражданской позиции, пробуждения интереса к российской и европейской культуре, гордости 
за свою страну я использую современные образовательные технологии: проектную, технологию «Развитие критического мышления через письмо», дистанционные образовательные технологии. В проектной деятельности я использую метод обучения в сотрудничестве, который предполагает парную и командную работу.

C 2005 года я являюсь координатором социокультурной практики учащихся в Лондоне (London City Business School и Westminster University. Ежегодно участники практики представляют свои отчеты-презентации в школе № 65 и гимназии № 31 .

В такой деятельности я вижу не только развитие коммуникативной компетенции учащихся, но и развитие умений толерантного взаимодействия учащихся между собой, умений уважать культуру других народов, достойно представлять свою культуру в диалоге культур.

Тематика школьных проектов разнообразна: «Интересные люди моего района», «Традиции моей семьи», «Моя родина - Уральские горы», «Мои соседи по Уралу», «Интернациональная Россия».

Таким образом, в ходе проектной деятельности учащиеся получают возможность участия в совместном планировании деятельности, прогнозировании её результатов.

В своей деятельности я успешно использую учебные Интернетпрограммы, они позволяют совершенствовать навыки учащихся по всем видам речевой деятельности. Я выступаю в роли тьютора сетевой дистантной образовательной программы Британского издательства OUP Oxford “HOT TIPS”, http://www.oup.co.uk информирую учителей методического объединения школы и учащихся 6-11 классов обо всех новых публикациях и новинках сайта ВВС Learning English (БИ БИ СИ Обучение английскому) http://www.bbc.co.uk/worldservice/learningenglish/

Для повышения качества знаний необходимо, чтобы все участники образовательного процесса - родители и учащиеся - чувствовали ответственность за образование. Я считаю, что родители - партнёры процесса образования, совместно с педагогом они создают условия ребенку для осознанного выбора дальнейшей образовательной траектории. Для стимулирования повышения индивидуального результата учащегося мы 
составляем рейтинг успеваемости, вместе с детьми обсуждаем проблемы, возникающие в процессе овладения иностранным языком, и совместно разрабатываем способы их решения. Таким образом, формируется гражданская позиция учащегося, когда он делает осознанный выбор способов и средств достижения образовательного результата.

Знания, полученные на курсах повышения квалификации «Проект концепции долгосрочной целевой программы «Развитие системы образования Пермского края на 2013-2017 годы», помогают мне в работе по совместному с учащимся планированию достижений каждого ученика. Результатом такого взаимодействия является стабильное повышение качества знаний учащихся и развитие ответственности детей за свой образовательный результат.

Продемонстрировать иноязычную коммуникативную компетентность учащиеся могут, принимая участие в олимпиадах, успешное выступление мотивирует их на дальнейшую работу над языком. Мои ученики принимают участие во Всероссийской олимпиаде по английскому языку; в региональной Оксфордской олимпиаде (учебный центр “Welcome"); в Международном игровом конкурсе «Английский Бульдог» ( ЦОК «British Bulldog» OОО «Центр продуктивного обучения» г.Санкт-Петербург); Дистанционном конкурсе «Чеширский кот» (Центр дистанционного образования «Эйдос», г.Москва); Международной олимпиаде по основам наук (представительство Чехии в г. Екатеринбурге); Олимпиаде «Олимпус» (ООО «ИРШО» г. Калининград). Выполнение заданий олимпиад способствует развитию мотивации на дальнейшее изучение иностранного языка, своей и иноязычной культуры. Задания олимпиад предполагают не только наличие знаний, но и нацелены на развитие мышления, умение предъявлять и защищать свое мнение, свою гражданскую позицию, поэтому я заинтересована в том, чтобы мои ученики принимали активное участие в олимпиадах различного уровня.

Систематическая работа по развитию мотивации к изучению английского языка привела к тому, что в 2010 году четверо моих учащихся успешно справились со сдачей международного экзамена IELTS при ПГНИУ.

Разработанная и апробированная мною авторская программа «Моя родина здесь!» для учащихся 1-11 классов способствует формированию и развитию умений представления культуры малой родины. В Программе глубже раскрыты 
имеющиеся в учебном плане темы о России, предусмотрены темы о Кировском районе города Перми (представлено 38 лексических тем).

Для развития умения рассуждать, я применяю технологию критического мышления через письмо, использую форму эссе. За долгую педагогическую практику у меня появился сборник работ учащихся - эссе на различные темы. Радует, что учащиеся умеют обосновать свою гражданскую позицию, чувствуют ответственность за своё образование, умеют выразить сочувствие, благодарность другим людям, готовы прийти на помощь. Моя методика работы по написанию эссе заинтересовала партнёров из Америки в рамках культурно образовательного обмена с Хоутон Колледж (Houghton College). Я была приглашена работать со студентами колледжа, преподавать в течение семестра 2009-2010 года методику написания эссе.

Очень эффективным стал Международный проект «Креативное письмо» совместно со школой в Фармвилле, штат Вирджиния, США (Farmville, state Virginia, the USA), целью которого является обучение ведению личной переписки по европейским стандартам. Два года мы с учениками 8-9 классов принимали участие в международном проекте «Международный урок Пермь (Россия) - Farmville (США)». Проект продемонстрировал высокий культурноязыковой интерес обеих сторон.

Таким образом, создаваемые условия способствуют достижению функциональной грамотности в овладении иностранным языком, наблюдается устойчивая позитивная динамика достижений в урочной и внеурочной деятельности обучающихся..

Я уверена, что в обучении и воспитании подрастающего поколения важно уделять внимание семейным духовным ценностям, традициям школы, изучению особенностей своей малой родины.

Воспитывать патриотизм нужно через любовь к своей семье, школе, городу. Как классный руководитель веду цикл классных часов на тему «Моя семья замечательна тем, что...». Ученики вместе с родителями включились в проектную деятельность. Результатом стало создание презентаций виртуального фотоальбома «Профессии в моей семье». Как продолжение, появился семейный Проект «Традиции моей семьи. Профессии семьи. Хобби. Фирменное блюдо», который диагностировал профессиональную ориентацию 
каждого ученика и раскрыл богатство традиций каждой семьи. Совместная деятельность детей и родителей вызывает у детей чувство гордости, сопричастности и желание продолжить дело родителей, таким образом вырабатывается умение сделать выбор своей будущей профессии, желание быть нужным людям. А это - гражданская позиция.

Совместная деятельность на мероприятиях класса накладывает ответственность за себя и за других, приобретается драгоценный индивидуальный социальный опыт толерантного поведения в классе, школе. Активное участие в жизни коллектива раскрывает границы творчества, рождаются идеи новых проектов, таких, как: школьный проект «Не забывайте учителей», проект класса «Добрый человек» позволяет каждому проявить свою толерантность. Акция «Чистый город», начавшаяся в городе и районе несколько лет назад продолжается до сих пор. Дети с желанием прибирают территорию школы, а также берег реки Кама.

Я разработала программу клуба «Корни». Первыми проектами родителей и детей стали проекты «Семейное древо», «Самая старая фотография семьи». Сейчас члены клуба ведут поисковую деятельность, работают совместно с учителями - ветеранами школы.

Как результат постоянной работы, направленной на создание комфортного микроклимата для учёбы и общения, для развития лидерских и организаторских качеств учащихся, а также в результате совместной деятельности всех участников образовательного процесса - в классах, где я была классным руководителем, 100\% успеваемость, 2 золотых, 4 серебряных медалиста, много участников региональных олимпиад по различным предметам.

Трижды в год провожу психологическую диагностику и коррекционную работу - СПТ (социально-психологические тренинги). На данный момент, по результатам тестирования уровня адаптации детей и социометрического обследования, микроклимат в классе благоприятный, что создаёт условия для успешного обучения и общения.

В работе с родителями также использую нетрадиционные формы, такие как тренинговые упражнения «Воспитывать - значит сотрудничать», «Общее семейное дело», «Позитив с утра», «Ситуация дискомфорта - путь к успеху!», которые вывели родителей на уровень дискуссии и раскрыли положительный 
родительский опыт. Тематические классные часы направлены на развитие нравственности: «Чувство долга», «Ответственен перед собой», «Даю слово!», «Я защищу тебя!», «Тебе нужна моя поддержка!»; на развитие патриотизма: «Я - частица мира», «Мой дом», «Традиции», «Мои соседи», «Подарки», «Школа среди сосен», «Горжусь тобою, Пермь!» С целью выстраивания поло-ролевых отношений в детском коллективе, я прежде учу мам позволять сыновьям заботиться о них, создавая такие ситуации не только в День 8 Марта, а ежедневно: «Записка для мамы», «Звонок маме на работу», «Ужин для мамы». Мальчики защищают проект «Лучший подарок для одноклассницы», а девочки - «Лучшее увлечение для одноклассника». Проявление заботы, творчества, тренировка публичного выступления ведёт к раскрытию личности и ее способностей, формируется чувство ответственности за тех, кто рядом.

В силу возрастных особенностей класса, постоянно проявляющейся проблемой становится создание в коллективе комфортной обстановки, посильное решение которой адресую самим детям под моим контролем. Любую ситуацию все вместе учимся анализировать. Это формирует толерантность, умение слушать и слышать другие точки зрения, а значит, уважительно относиться друг к другу.

Свой педагогический опыт я обобщила на городской научно практической конференции «Язык и духовность» в докладе «Воспитание гражданина на уроках английского языка, во внеурочной деятельности и классном руководстве» и на районной научно-практической конференции «Пути модернизации современного урока с позиции компетентностного подхода в образовании», на городских и районных семинарах, а также представлена через мастер-классы.

Мой опыт патриотического воспитания представлен на сайтах: Педсовет.org, Прикамский Народный Собор; Социальная сеть работников образования; Сообщество Взаимопомощи учителей; Научный Информационноаналитический журнал «Образование и общество» №4, 2010 год, а также в Хрестоматии «Образовательная среда современного общества», С-Петербург, 2013 год.

Мой многолетний опыт по обучению и воспитанию детей показывает, что только во взаимодействии педагога, ребёнка и родителей, через проектную 
деятельность, через рефлексию своей деятельности, в совместном творческом поиске, происходит, с одной стороны, становление и развитие профессионального мастерства учителя, с другой стороны, максимальное раскрытие потенциала ученика, его личностное самоопределение и становление гражданской позиции. 


\section{Литература:}

1. Агапова И. Патриотическое воспитание в школе : сборник сценариев внеурочных мероприятий / И. Агапова, М. Давыдова. - М. : Айрис-Пресс, 2010. -224 c.

2. Евграфова Ю.А.- Ценности современной молодежи и установка на семью и деторождение//Известия ПГПУ им. В.Г.Белинского.2012. N 28.c.12131216.

3. Зеленова Н.Г, Осипова Л.Е.- Мы живем в России. Гражданскопатриотическое воспитание школьников - М.: Скрипторий, 2011. - 104 с.

4. Никандров, Н. Д. Воспитание ценностей: российский вариант [Текст]/ Н.Д. Никандров. - М.: Магистр, 1996. -99,[1] с. -Библиогр.:96-99с.

5. Никандров, Н. Д. Россия: ценности общества на рубеже XXI века [Текст]/ Н.Д. Никандров. - М.: МИРОС, 1997. -140,[1] с.: табл. -Библиогр.:132-140с. 